\title{
Editorial
}

\section{Sinusitis to Relaunch}

\author{
Franck Vazquez
}

MDPI, St. Alban-Anlage, 66, CH-4052 Basel, Switzerland; vazquez@mdpi.com

Received: 18 December 2019; Accepted: 18 December 2019; Published: 20 December 2019

Since its inception in 2016 Sinusitis has published 25 articles on the topic of rhinitis, rhinosinusitis, nasal polyps, surgery in diseases of the upper airways, and new techniques and methods to investigate and treat upper airways disease [1].

Sinusitis became Sinusitis and Asthma in August 2018, but due to a lack of resources, Sinusitis and Asthma was not able to accept submissions in 2019. On behalf of the Editorial Board and the Editorial Office, it is our pleasure to announce that Sinusitis will remain the title of the journal and is now once again able to actively publish peer reviewed articles, and has therefore reopened for submissions. Articles will be published online immediately after acceptance and production. We wish to thank all authors, reviewers and academic editors, especially the Editor-in-Chief Professor Picado, for their support over the past years, and welcome them to join us in developing Sinusitis as one of the leading journals reporting studies on diseases of the respiratory tract.

Conflicts of Interest: The authors declare no conflict of interest.

\section{Reference}

1. Picado, C. Change of Title: Sinusitis Becomes Sinusitis and Asthma. Sinusitis Asthma 2018, 3, 7. [CrossRef]

(C) 2019 by the author. Licensee MDPI, Basel, Switzerland. This article is an open access article distributed under the terms and conditions of the Creative Commons Attribution (CC BY) license (http://creativecommons.org/licenses/by/4.0/). 